\title{
A abordagem relacional no estudo da gestão e das políticas públicas: das relações às associações
}

\author{
Gustavo Onto ${ }^{1}$ \\ Gabriela Toledo Silva ${ }^{2}$
}

\begin{abstract}
RESUMO: Uma série de estudos que buscam compreender a gestão pública e a formulação e execução de políticas públicas passou a adotar uma abordagem teórica relacional desses fenômenos. Contudo, a grande variedade de perspectivas incluídas nessa abordagem dificulta a compreensão de sua importância para a pesquisa nessa área. Este ensaio pretende fazer uma breve apresentação dos modos de utilização e interpretação daquilo que é denominado como relacional. São apresentadas as perspectivas que tratam o relacional como procedimento metodológico, como metáfora organizacional e como ontologia de construção da realidade. Busca-se com isso contribuir para uma mais clara percepção da importância da abordagem relacional, de seus limites e possibilidades.
\end{abstract}

PALAVRAS-CHAVE: Políticas públicas, gestão pública, análise de redes sociais, actor-network theory.

ABSTRACT: A series of studies directed at public governance and policy formulation and implementation have recently started to adopt a theoretical relational approach to these phenomena. However, the large variety of perspectives included in this approach difficult the understanding of its importance to the research in this area. This essay intends to briefly present the ways these perspectives are used and the different ways the relational aspect is interpreted. We present perspectives that deal with the relational as a methodological procedure, as an organizational metaphor and as an ontology of the construction of reality. We intend to contribute towards a clearer perception of the importance of the relational approach, of its limits and possibilities.

KEYWORDS: Public policies, government, social network analysis, actor-network theory.

\footnotetext{
${ }^{1}$ Mestre em Administração Pública e Governo pela Escola de Administração de Empresas de São Paulo da Fundação Getulio Vargas. Avenida Nove de Julho, 2029, São Paulo - SP, 01313-902. E-mail: gustavo.onto@gmail.com.

${ }^{2}$ Mestre em Administração Pública e Governo pela Escola de Administração de Empresas de São Paulo da Fundação Getulio Vargas e pesquisadora do Centro de Estudos em Administração Pública e Governo da Fundação Getulio Vargas. Avenida Nove de Julho, 2029, São Paulo SP, 01313-902. E-mail: gatoledosilva@gmail.com.
} 


\section{Introdução}

A abordagem relacional surgiu há bastante tempo na teoria social, especialmente dentro dos campos da sociologia e antropologia. Contudo, a sua utilização nos estudos sobre a burocracia, a gestão pública e as políticas públicas surgiu apenas recentemente devido à uma maior percepção da importância das relações humanas no processo político. Segundo Thompson (2003), esse interesse decorre de uma mudança na percepção de como as sociedades funcionam, resultantes de transformações sociais do período. Entre essas mudanças estão: (a) o surgimento de uma sociedade civil organizada; (b) uma tendência de setorização e especialização na formulação de políticas; (c) um aumento da mobilização de interesses organizados nas redes políticas; (d) um aumento na variedade de políticas estatais; (e) a descentralização do Estado; e (f) o relativo desaparecimento das fronteiras entre o público e o privado. Esses estudos apresentam a política operando num ambiente organizacional desagregado e descentralizado, agrupado em uma forma de negociação coletiva e cooperação, entendendo as redes como mecanismos de mobilização política, influência social ou intermediação de interesses (ANSELL, 2000). A literatura da abordagem relacional produziu uma série de conceitos para compreender as relações sociais e seu impacto na gestão e formulação de políticas como issue networks, policy networks, policy domains, policy community, networked policy, entre outros. Estes conceitos buscam "reinserir os atores em seus contextos institucionais e relacionais, ou associar as estruturas de poder aos contextos institucionais em suas estruturas relacionais.” (MARQUES, 2006). O pressuposto básico desta visão epistemológica (e em alguns casos ontológica) pode ser chamado de imperativo “anti-categórico", ou seja, a "rejeição das tentativas de explicar o comportamento humano e processos sociais somente em termos de atributos categóricos de atores, coletivos ou individuais” (EMIRBAYER e GOODWIN, 1994). Ao contrário, a posição de um indivíduo dentro de um ambiente social específico é que molda seu comportamento e sua identidade.

Apesar do volume e relevância dos trabalhos que foram desenvolvidos caracterizando uma abordagem predominantemente relacional, percebe-se ainda certa incompreensão sobre seu significado. Diz-se que falar de redes é "óbvio" e claro. Encontra-se, inclusive, alguma aversão a falar do assunto, especialmente entre cientistas políticos. A introdução da variável rede questiona, por um lado, concepções e categorias analíticas já sedimentadas que compartimentam as unidades de análise e facilitam a inferência de regularidades e ciclos na vida política. Mas, para, além disto, acreditamos que possa haver um outro motivo que dificulta sua compreensão, com o qual 
nós mesmos nos deparamos ao iniciar o estudo de redes, atores-redes, políticas em rede e sociedade em rede. Ela advém da grande quantidade e, principalmente, da diversidade das propostas, estudos e teorias que tratam do aspecto relacional e das maneiras como ele deve ser analisado e interpretado (KNOX, SAVAGE e HARVEY, 2006). As redes, objetos de estudo da análise relacional, são estudadas e definidas de muitas maneiras e, de modo geral, os trabalhos empregam inúmeras técnicas e metodologias de pesquisa. O presente ensaio pretende lidar com esse segundo motivo, tentando reunir e sintetizar algumas dessas abordagens, apontando suas semelhanças e diferenças, de modo que se possa enxergar na multiplicidade, um conjunto articulado de contribuições para o estudo de políticas públicas e gestão.

Para isso, far-se-á uma revisão e breve apresentação de trabalhos e teorias relacionais que podem ser adotados nos estudos de gestão e política pública. Mais especificamente, são definidas três perspectivas relacionais que consideramos importantes para compreender a atividade do governo: a análise de redes sociais (ARS), o Insitucionalismo de Redes, e a Actor-Network Theory (ANT). A primeira utiliza a rede como instrumental analítico ou metodologia que, suportada por dados de natureza quantitativa e análise matemática, procura identificar estruturas relacionais que condicionam certos processos sociais. A segunda, aqui denominada Institucionalista, concebe a rede como um tipo de lógica organizacional, uma maneira de governar relações entre atores políticos e sociais. As redes são trabalhadas como formas de governança, por serem capazes de aglutinar indivíduos e organizações dentro de um determinado sistema. Referimo-nos, neste caso, a estudos cujos recortes empíricos incorporam a dimensão das relações ou organizações em rede enquanto fenômeno empírico, mas elas não constituem necessariamente a unidade básica de análise. A última perspectiva relacional, a ANT, vai mais longe na compreensão do aspecto relacional, do qual participam atores humanos e não humanos, entendendo-o como constitutivo básico da realidade social. As actor-networks são programas antropológicos de construção da realidade, construídas por humanos e pelas materialidades, ambos com capacidade de agência. A conclusão do ensaio trata das principais contribuições dessas três perspectivas para o estudo da gestão e das políticas públicas, observando particularmente as diferentes perguntas que o pesquisador deve fazer ao utilizar uma abordagem relacional. 
A Análise de Redes Sociais (ARS): o relacional como metodologia

O aspecto relacional começou a ser tratado na teoria social por Émile Durkheim e Georg Simmel (DOBBIN, 2006; EMIRBAYER e GOODWIN, 1994). Para Durkheim, as redes sociais modelam as ações dos indivíduos não somente num sentido negativo, reprimindo comportamentos antisociais, mas também positivamente, estabelecendo padrões de comportamento aceitáveis (DURKHEIM, 1964). Simmel (1971) desenvolveu uma vasta teoria de interações e relações sociais, criando uma chamada "sociologia formalista" e a aplicou a diversos campos de investigação. A mais tradicional e institucionalizada perspectiva de abordagem relacional é a chamada análise de redes sociais (ARS), constituindo praticamente uma escola teórica, sendo seus integrantes geralmente sociólogos. Entre os primeiros formuladores dessa perspectiva estão os sociólogos Mark Granovetter, Edward Laumann e Harrison White, e os antropólogos Elizabeth Bott e John Barnes. Esses trabalhos começaram a ser desenvolvidos na década de 70 e apresentaram-se como uma alternativa a abordagens culturalmente deterministas (oversocialized), visto que permitiam um espaço para a agência do indivíduo, e abordagens individualistas, atomizadas (undersocialized), já que também enfatizavam a estrutura e as contingências (GRANOVETTER, 1985; SMITH-DOERR e POWELL, 2006).

Segundo a ARS, os atores sociais (organizações, grupos ou indivíduos) estão imersos em relações sociais, que caracterizam sua ação. Como diz Granovetter (1985), "actors do not behave or decide as atoms outside a social context, nor do they adhere slavishly to a script written for them by the particular intersection of social categories that they happen to occupy. Their attempts at purposive action are instead embedded in concrete, ongoing systems of social relations". Para a ARS a rede constitui um: "specific set of relations making up an interconnected chain or system for a defined set of entities that form a structure" (THOMPSON, 2003). A rede caracteriza, portanto, o sistema formado pelos vínculos diretos e indiretos entre os atores (STEINER, 2005). De acordo com Granovetter (1973), redes sociais são "como um conjunto de nós ou atores ligados por relações sociais ou laços de tipos específicos. Um laço ou relação entre dois autores tem força (strength) e conteúdo. O conteúdo inclui informação, conselho ou amizade, interesses compartilhados ou pertencimentos e, tipicamente, algum nível de confiança" (GRANOVETTER; et al. 1998: 219). A unidade de análise, por sua vez, concentra-se na existência de relações entre unidades ou entidades. Pode-se distinguir cinco características da abordagem de ARS 
(THOMPSON, 2003): (i) os atores e suas ações são tomados como interdependentes, em vez de autônomos; (ii) os laços relacionais formados pelas redes são concebidos como uma "estrutura"; (iii) esses laços são canais para a transferência de recursos, materiais ou simbólicos; (iv) o ambiente estrutural da rede proporciona oportunidades ou constrangimentos para a ação individual; e (v) as redes sociais estabelecem padrões de relacionamento de longo-prazo entre atores.

O número de estudos utilizando análise de redes é imenso e desenvolveu uma grande tipologia de relacionamentos possíveis entre atores sociais. Ademais, vários 1conceitos foram desenvolvidos para se entender melhor o comportamento das redes sociais. Harrison White desenvolveu o conceito de equivalência estrutural (structural equivalence), em que dois atores ocupam posições similares num sistema social, pois possuem laços de rede estruturalmente comparáveis. Mark Granovetter (1973; 1974) criou o conceito de laços fracos (weak ties) para explicar o mercado de trabalho, e pôde concluir que esses laços são mais relevantes para a análise, pois são capazes de interconectar grupos com diferentes qualidades de informação. Ronald Burt utilizou-se das ideias de Simmel para entender o papel de ponte (bridges) entre atores que não se relacionam diretamente um com o outro, formando um buraco estrutural (structural hole) (BURT, 1992). Solidariedade, altruísmo, lealdade, reciprocidade e confiança são alguns dos atributos que identificam redes sociais na perspectiva da ARS (THOMPSON, 2003). Todos esses desenvolvimentos teóricos proporcionaram ao pesquisador que utiliza a análise de redes entender os impactos que as redes geram nas relações sociais, no fluxo de informações e nas organizações. As redes são, para a ARS, variáveis críticas de mediação que afetam a distribuição de poder, a construção de interesses e identidades e a dinâmica da interação social (ANSELL, 2000). Essa perspectiva salienta, fundamentalmente, as diferentes capacidades de ação dos atores sociais, baseadas na habilidade de mobilizar conexões de diferentes domínios da vida política, econômica e social (SMITH-DOERR e POWELL, 2006).

Hugh Heclo (1978) foi um dos primeiros estudiosos do papel das redes na política. Seus estudos sobre o Departamento do Tesouro Britânico e políticas norte-americanas permitiram criticar a ideia de que as políticas eram dominadas por "triângulos de ferro" entre legisladores, burocratas e atores privados. Heclo cunhou o termo issue network para se referir a redes de assuntos específicos que alcançam atores muito mais distantes dos espaços formais geralmente analisados. Outros trabalhos começaram a diferenciar as estruturas internas das redes e articular os 
mecanismos pelos quais elas funcionam. Rhodes (1985) distinguiu seu conceito de policy communities do conceito de Heclo de issue networks. O primeiro é caracterizado por um conjunto relativamente estável de participantes interdependentes, coexistindo numa rede relativamente fechada. Esses agentes formam uma comunidade de valores e normas que é dificilmente rompida, tornando a entrada de novos participantes quase impossível (THOMPSON, 2003). O segundo apresenta uma configuração de rede mais aberta, distinguindo-se do primeiro quanto à estabilidade e restrição de acesso à rede (ANSELL, 2006). Ou seja, no caso das issue networks, o poder é mais difuso e mais atores participam da formulação da política pública, tornando difícil encontrar um grupo de responsáveis pelo resultado final. Esses estudos enfatizaram que a formulação e implementação de políticas públicas requerem uma coordenação e negociação complexa entre diferentes atores políticos.

Nessa mesma direção, Laumann e Pappi (1973) estudaram as relações entre a elite de uma pequena cidade alemã e descobriram que as redes podem melhorar ou restringir a capacidade de ação coletiva de modo a afetar as políticas da comunidade. As redes encontradas são definidas como atores coletivos, um conjunto de organizações que ocupam a mesma posição estrutural na rede e possuem laços de comunicação fortes, tendo assim preferências idênticas de resultados políticos. Essas redes de políticas (policy networks) são formadas por atores públicos e privados e suas fronteiras não são determinadas por instituições formais, resultando de um processo de reconhecimento mútuo dependente da relevância funcional do ator ou de sua inserção estrutural na rede (KNOKE, 2003). Mais recentemente, estudos começaram a utilizar o conceito de national policy domain numa tentativa de flexibilizar a ideia de redes apenas entre elites e atores bem definidos. O trabalho de Laumann e Knoke (1987) sobre as redes de políticas norteamericanas enfatiza como a comunicação inter-organizacional por meio de redes constroi campanhas de ação coletiva entre grupos de interesse específicos. Os "domínios de políticas" são o conjunto de organizações, instituições legislativas e agências governamentais executivas que se empenham em construir agendas, formular políticas, ganhar acesso, conquistar posições e selecionar propostas para resolver problemas de políticas públicas.

Apesar da ampla produção e desenvolvimentos teóricos e conceituais nesse campo, estudos focados na perspectiva da ARS deixaram muitas questões a serem resolvidas. Os conceitos e trabalhos não cobriam todo o espectro da formulação de políticas públicas e da capacidade de gestão governamental. Cultura, ideias, ideologias, discursos, o papel de atores, poder, fatores

CADERNOS GESTÃO PÚBLICA E CIDADANIA, V. 13, N. 53 - JUL/DEZEMBRO 2008 
econômicos e tecnológicos, contextos macro-institucionais e questões de mudança institucional são elementos que foram deixados de lado nessa análise formalizada das relações sociais dos atores políticos (THOMPSON, 2003). Como se verá, perspectivas relacionais menos formalizantes (matemáticas), menos estruturalistas e instrumentalistas, acabaram podendo tratar de outros elementos tão importantes quanto a simples conectividade entre atores sociais. Mesmo assim, a ARS constitui uma poderosa perspectiva contra o individualismo metodológico tão em voga na ciência econômica e na ciência política.

\section{O Institucionalismo de Redes: o relacional como metáfora}

O segundo conjunto de estudos que enfatizam o aspecto relacional é formado por aqueles que não adotaram explicitamente as redes como recurso metodológico e não desenvolveram tantos conceitos para entender as redes sociais na políticas públicas, mas se utilizaram de uma ideia mais ampla de redes para explicar a relação entre estado e sociedade, políticas de desenvolvimento local, surgimento de capital social e movimentos sociais. Suas considerações e análises proporcionam novas direções e novas perspectivas para se estudar aspectos relacionais. Observa-se que esse quadro sucinto de autores e temas de pesquisa, embora agrupe autores muito distintos entre si, apresenta alguns princípios básicos em comum, característicos de uma abordagem de redes mais ampla ou, como diz Ansell (2006), de um “Institucionalismo de Redes” (Network Institutionalism). São eles: (a) uma perspectiva relacional da ação humana e organizacional, em vez de uma perspectiva que impõe atributos ao agente; (b) tendência à complexidade, visto que as organizações e relações não são claramente identificáveis e não compõem um grupo homogêneo; (c) as redes proporcionam recursos e constrangimentos ao comportamento do agente; (d) as redes são diferenciadas, ou seja, apresentam uma variedade de formas de acesso a recursos e informações (ANSELL, 2006). Observa-se que esses princípios são mais amplos do que aqueles tomados como base pelos estudos que utilizam a análise de redes sociais stricto sensu, conforme exposto na seção anterior.

Na área de estudos de políticas de desenvolvimento, por exemplo, as discussões passaram a desafiar a tradicional dicotomia entre Estado e sociedade, em que o Estado formularia políticas para governar a sociedade (ANSELL, 2000). Peter Evans, outro exemplo, utiliza-se da ideia de state-society synergy para compreender o sucesso de políticas sociais em países em 
desenvolvimento (EVANS, 1996). Em seu livro Embedded Autonomy: States and Industrial Transformation, Evans procura especificar tipos de relações entre agentes do Estado (burocracia) e agentes sociais (elites industriais) que permitiram desenvolver políticas industriais com maior sucesso entre países em desenvolvimento. As nações bem-sucedidas possuiríam Estados que "são inseridos em um conjunto concreto de laços sociais que une o Estado à sociedade e provém canais institucionalizados para a contínua negociação e renegociação de objetivos e politicas" (EVANS, 1995). Essa perspectiva foca no estudo das estruturas intermediárias de associação (ou governança) entre a Sociedade Civil e o Estado (ANSELL, 2000; AMIN e THRIFT, 1995). São exemplos dessa perspectiva os trabalhos dos geógrafos Ash Amin e Nigel Thrift, que procuram descrever o que seria um novo modelo de desenvolvimento para a Europa, especialmente para as regiões menos desenvolvidas. Suas conclusões normativas constituem um modelo para a formulação de políticas com os seguintes pontos: (a) uma negociação “interativa” entre sociedade civil e poder publico em vez de uma abordagem top-down na formação de políticas e de instituições; (b) politicas públicas contextualmente situadas; (c) construção institucional negociada em contraposição a uma imposição institucional; (d) e formas de governança intermediárias como instrumento de consolidação institucional (AMIN e THRIFT, 1995). Esse modelo de desenvolvimento "associativista" procura, basicamente, reforçar as redes institucionais locais.

A abordagem relacional teve também um impacto significativo nos trabalhos sobre mobilização política e movimentos sociais. Entre os trabalhos, em grande parte históricos, destacam-se as análises de Bearman (1993), sobre a maneira como a facção puritana na Guerra Civil Inglesa surgiu de redes de patronagem religiosas, o estudo de Padgett e Ansell (1993), demonstrando como o controle do Estado florentino pela família Medici baseou-se na mobilização de um partido político poderoso construído por laços econômicos e de casamento, e Gould (1995), que demonstrou que a resistência nas barricadas da Comuna de Paris de 1871 foi baseada em redes sociais formadas nos bairros. Diani (1995) utiliza a abordagem de redes para descrever as relações entre organizações ambientais e ativistas do meio-ambiente em Milão. Na área de relações internacionais, Keck e Sikkink (1998) analisaram as redes internacionais de ONGs para entender a formação de grupos de pressão internacionais, denominando-as de transnational advocacy networks. Em geral, esses estudos mostraram que as redes sociais são responsáveis pelo 
recrutamento em movimentos sociais, por engajamento em causas coletivas, e por processos históricos de mudança social (DIANI e MCADAM, 2003).

Os estudos apresentados, categorizados aqui como do Institucionalismo de Rede, possibilitaram o desenvolvimento teórico da abordagem relacional e sua expansão em direção a perspectivas menos estruturalistas. Pode-se argumentar que o Institucionalismo de Redes permitiu avançar em três novas direções: (i) na definição de um novo modelo de formulação e gestão de política pública; (ii) na inserção de categorias intangíveis como a cultura, discursos e ideias; e (iii) na utilização de análises que dessem ênfase à agência humana. Em primeiro lugar, os estudos passaram a entender a formulação e gestão de políticas como se a política fosse inerentemente relacional. A ideia de "Política em Rede" pretende conceitualizar o domínio ou campo da política como um ambiente desagregado e descentralizado, agrupado em uma forma de negociação coletiva e cooperação (ANSELL, 2000). De acordo com essa visão, a unidade de planejamento e administração é um “time” multi-organizacional, relacionado a um projeto específico, que transcende as fronteiras entre o público e o privado, o domínio de diferentes agências governamentais, e as jurisdições verticais e horizontais do Estado (ANSELL, 2000). Esse conceito transforma a noção tradicional weberiana do modo de funcionamento da burocracia: de “programas” (planos) e funcionários dedicados ao processamento de rotinas e tarefas, para “projetos” (associações), em que os participantes e lideranças mudam dependendo da natureza do projeto (AMIN e THRIFT, 1995; ANSELL, 2000). Diferentes unidades de uma mesma organização ou de uma mesma agência governamental estarão direcionadas, simultaneamente, a distintos projetos em redes parcialmente autônomas. As outras duas direções serão tratadas na conclusão, visto que foram abordadas pela ANT, explicada na próxima sessão.

Uma característica marcante do Institucionalismo de Redes é que o aspecto relacional não apenas é utilizado como metáfora, mas também como elemento normativo, sendo fundamental para o desenvolvimento local, a democracia e a eficiente gestão pública. Partindo do pressuposto de que os recursos e conhecimentos que compõem a política pública são distribuídos entre organizações diversas, tanto do setor público como do privado, a governança por meio de redes deve focar não os domínios excludentes de cada política pública, mas sim em formas de cooperação entre esses recursos e autoridades difusos, societais e estatais (ANSELL, 2000). Assim sendo, para administrar melhor é necessário criar formas de cooperar melhor. A política em rede seria um modelo mais eficiente de organização sócio-política. Ainda, a política em rede pode ser mais 
democrática ou representativa. Neste sentido, temos uma espécie de representação política "alongada e estendida, funcionando por meio de uma pluralidade de organizações e formas associativas (...) governando interesses privados de uma forma cada vez mais pública” (Thompson, 2003). Segundo Stark e Bruzst (1998), a representação é entendida como “a imbricação dos centros de tomada de decisões em redes de instituições políticas autônomas que limitam a arbitrariedade dos governantes no poder. Responsabilidade política estendida difere, primeiro, da responsabilidade "vertical" das eleições periódicas, pois ela estende a responsabilidade "horizontalmente" em um conjunto de relações através das quais os executivos são forçados à responsabilidade política por outras instituições estatais. Expondo as políticas a maior vigilância, a responsabilidade política estendida reduz a possibilidade de os executivos cometerem enormes erros de cálculo em políticas extremas e sem consideração para com outros atores. A responsabilidade política estendida se diferencia, em segundo lugar, da simples responsabilidade eleitoral porque, ao contrário do caráter episódico desta última, ela é estendida no tempo.” Se concordarmos com Stark e Bruszt, vemos que a política, sendo feita desse modo, possui maiores chances de sucesso. O sucesso ou não dessa visão de processo político deverá ser analisado caso a caso, tendo como base uma teoria democrática representativa mais ampla.

\section{Actor-Network Theory: o relacional como ontologia}

Ao contrário da ARS e do Institucionalismo de Redes, a actor-network theory (ANT) foi amplamente aplicada no estudo da difusão de inovações na ciência e na tecnologia e, só mais recentemente, seu arcabouço conceitual passou a integrar alguns estudos sobre políticas públicas e governança (ver SPINK, 1998, para o estudo das narrativas sobre a Reforma Administrativa do setor público no Brasil e SMULLEN, 2004, para uma análise das ideias e categorias relacionadas ao programa de "agencificação" do governo holandês). Isso se deve, em primeiro lugar, à separação entre o domínio do fazer científico e do político. Em segundo, porque o tipo de análise possibilitada por uma abordagem como a ANT responde a perguntas substancialmente diferentes daquelas propostas pelas abordagens anteriores. A ANT permite olhar para as políticas públicas sem partir de um pressuposto normativo sobre o que deve ser feito, e nem sobre quem é o sujeito e o objeto da ação (ou da política). Assim, a pergunta do pesquisador que estuda as políticas públicas se desloca da busca de lógicas causais para passar a avaliar as políticas de acordo com 
suas próprias categorias e construções. Se as abordagens de redes já apontavam para os ambientes interorganizacionais e sugeriam uma agência mais distribuída e menos predeterminada do que na epistemologia clássica, segundo a qual a sobredeterminância de uma causalidade é mutuamente exclusiva e polarizada entre ação individual e estrutura social, veremos que, ao olhar mais atentamente para as práticas discursivas, produzidas na constituição das políticas públicas, e ao incluir nas redes elementos de tipos diversos, humanos e não humanos, torna-se possível mapear seus processos sem antecipar a identificação de seu agente principal.

A actor-network theory (ANT) é um tipo de teoria social que critica as bases da epistemologia sociológica e seus conceitos iniciais foram desenvolvidos nos anos 80 por Michel Callon (1986) e Bruno Latour (1987). Partindo dos estudos em difusão de inovações na ciência e na tecnologia, conhecidos como science and technology studies (STS), a ANT também conceitua interações sociais em termos de redes. Porém, as redes da ANT não são formadas exclusivamente por pessoas, ou por assuntos. Elas integram o ambiente material e o ambiente semiótico, e isso faz com que sejam portadoras de técnicas e práticas ao mesmo tempo que de discursos e significados (CALLON, 2001). Isto implica que nas interações sociais, ou nos nós da rede, interagem os atores políticos mais conhecidos por nós, as pessoas, mas também suas narrativas, os textos que produzem, os documentos nos quais os textos e narrativas são oficializados, os equipamentos burocráticos necessários para sua oficialização e os equipamentos sociais necessários para a legitimação do conjunto de práticas nas quais se inserem. Assim, para entender a ação política para além dos atores políticos usuais é necessário observar mais detidamente os textos, documentos e materialidades que agregam e transportam discursos e enunciados capazes de facilitar ou dificultar uma determinada ação. De um lado, a ANT enfatiza o papel ativo que as inscrições - modalidades que tornam visíveis e acessíveis as informações - têm na construção de fatos e, portanto atuam como objetos na constituição das políticas (LATOUR, 1987; 2004; 2005). De outro, ela ajuda a mostrar que os lugares onde acontecem as decisões politicamente relevantes não coincidem com os perímetros organizacionais e institucionais, aos quais se costuma recorrer no estudo de políticas públicas, mas sim com os lugares onde os elementos envolvidos agem conforme e sobre outros actantes (Latour, 2005; Callon, 2006), de forma a conseguir que as visões de mundo e os veredictos se ratifiquem mutuamente nas negociações cotidianas (Bevriglieri, 2004; Star \& Griesemer, 1989). Assim, descarta-se uma divisão funcional entre quem ou o quê formula regras e quem as aplica. As concepções e veredictos passam a ser, 
respectivamente, o lado abstrato e o lado prático de uma mesma ação. (GEERTZ, 1997 [1983]: 271).

A ANT propõe uma metodologia de análise na qual se presume que existam associações e vínculos entre os elementos constitutivos de uma política pública, mas não é antecipada a natureza desses elementos e nem a sobredeterminância causal entre um e outro (LATOUR, 2005:55). O objetivo da ANT não é superar a contradição agente-estrutura, mas um modo de prestar atenção a estas insuficiências, segui-las e persegui-las na tentativa de explorar as condições mesmas que as fazem insuficientes (LATOUR, 1999). Desenvolve-se então uma estratégia analítica - mais do que uma teoria - para compreender a trajetória, o movimento, a circulação da agência, entre o micro e macro. Constitui-se um mesoespaço analítico de interação e circulação de agentes. As instituições têm uma materialidade, as ideias são objetivadas, as ações ocorrem num espaço determinado, e os suportes materiais de instituições abstratas tornam-se mais do que um veículo, são o locus da ação, e como tal suas características interagem com a ação em si. Se da agência não podem ser determinados o seu tamanho, sua força ou a natureza de sua atuação na realidade; se ela precisa ter como efeito a realidade; se nela é preciso incluir o discurso e outros objetos; e se ela designa fluidamente o agir individual e o coletivo, é ponto pacífico que deva ser performativa. Mas, o que é a performatividade? O estudo de Timothy Mitchell (2002) sobre a tecno-política pós-colonial egípcia é um bom exemplo do processo de performatividade. Segundo ele, economistas, teoria econômica, mapas, geógrafos, usinas hidrelétricas e até o Rio Nilo são elementos da actor-network que ajudaram a tornar "realizável" uma economia nacional egípcia. A economia egípcia só existe quando é performada por políticas que se dirigem ao "econômico". A economia ou o Estado-nacional egípcio não são realidades autônomas que os economistas e cientistas políticos tentam entender. Os últimos tornam realidade os primeiros. E esse processo ocorre por meio de negociações, lutas de significados, conflitos e todo trabalho e custo de estabilização que deixam de ser percebidos ou levados em conta, passando a agir associadamente como uma força única e universal. Torna-se uma caixapreta (LATOUR, 1981: 299). Mas considerando que quase tudo no mundo se situa entre os distantes extremos da total incerteza e de um fato 'caixa-preta', Latour sugere que o foco dos estudos sociais recaia na capacidade de associação de pessoas, coisas, objetos e textos, já que ninguém sabe quantas pessoas trabalham simultaneamente - ou quantos e quais elementos são 
mobilizados - em um indivíduo, nem o quanto há de individualidade numa 'nuvem de pontos de dados estatísticos' (LATOUR, 2005: 54).

O conceito ontological politics, cunhado por Mol (1999), coloca o político e a possibilidade do real no mesmo nível: a realidade não precede as práticas mundanas através das quais interagimos, ela é moldada por estas práticas. A palavra política enfatiza este modo de ativação, de dar forma, nome, endereço e vida àquilo que se quer decidir sobre. Este processo concomitantemente cognitivo e interventor, que apreende e constroi a realidade, é chamado de performatividade. A realidade e os fatos são feitos e performados, ao invés de observados. Isso implica que não existe distinção entre uma decisão técnica, fruto da observação imparcial e científica de dados, e uma decisão política, pautada por interesses de grupos que disputam o poder. A política pública, como modalidade de ação situada, agrega os instrumentos que definem seus objetos à sua própria constituição. Nessa perspectiva, os discursos e objetos produzidos pelos atores não são descolados da realidade. Eles constituem a realidade. Logo, são artefatos que integram as redes e transportam, eles mesmos, associações de discursos e significados. Michel Callon (2007) defende que qualquer discurso age sobre seu objeto, mais especificamente, que os enunciados, teorias, modelos e fórmulas desenvolvidos por economistas constróem e modificam a economia. As descrições do mundo, segundo ele, produzem traços que podem se tornar pontos de passagem obrigatórios para que uma realidade se materialize (2007: 41). Portanto, para que exista uma política pública, há que se recriar constantemente a noção de ‘público’, usando os instrumentos que tornam apreensíveis esta noção.

Estes instrumentos - os discursos, enunciados, teorias, codificações e objetos - são chamados de sociotecnologias. Segundo a abordagem da ANT, os enunciados e proposições fazem parte daquilo que descrevem, portanto não há um universo de referentes fora do mundo dos enunciados. O espectro de ação de uma política pública é definido pelas estatísticas, mapas, gráficos, fotografias, narrativas identitárias, descrições de problemas, ilustrações e tantos formatos diagnósticos quantos forem necessários para criar um território apreensível e passível de intervenção e posicionamento político. Os instrumentos de visibilidade e padronização de informações deixam de ser apenas lentes para o mundo e tornam-se artefatos que agregam o político e o técnico, intervém na realidade em que estão inseridos e por isso são chamados de sociotecnologias. As sociotecnologias podem ser entendidas como formas associativas de agência que transportam associações entre discursos, pessoas, técnicas e informações em diferentes 
suportes e materiais, sendo que quanto maior o número de associações e mais amarradas elas forem, maior sua capacidade de circulação e sua centralidade estratégica como fato taken-forgranted. As sociotecnologias agem em redes de interações entre pessoas e objetos, e a ação coletiva é re-conceituada em termos da força que uma associação desta variedade de elementos pode ter ao mobilizá-los (LATOUR, 1987). O termo atores-rede ou actor-networks designa uma trama de associações inter-níveis, cuja força está na capacidade de constituição de fatos que são considerados como tal e se tornam praticamente inquestionáveis, como caixas-pretas. As caixas pretas omitem pragmaticamente todo o trabalho de associação de sociotecnologias e artefatos que está por trás da constituição de um fato. Se as sociotecnologias são formadas pela interação de pessoas, máquinas, artefatos, textos, aproximando a construção social da construção material da realidade, a materialidade é a evidência ou inscrição das associações que constituem o agir político. Portanto, os documentos, artefatos, lugares e caminhos não são meros registros ou suportes de significado, embora possam funcionar como um meio se construírem relações indiciárias com outras materialidades. A burocracia estatal pode ser entendida como um agregado de propriedades físicas e socio-culturais que implicam na coordenação de interações interpessoais documentadas, como reuniões, telefonemas, e-mails, memorandos, relatórios, atas, pronunciamentos, etc. Para que isso aconteça, os espaços devem estar equipados e materialmente arranjados de forma que não só facilite a execução destas tarefas, mas geralmente esta disposição material descreve também uma analogia à hierarquia dos cargos e das tarefas do dia-a-dia (CICOUREL, 1981). Arranjos que parecem, a primeira vista, aleatórios ou puramente organizacionais ou funcionais, são vistos pela ANT como produtores de cenários relevantes e decisivos para a atuação social e política. Eles são os elementos que o pesquisador vai se preocupar, descrever, questionar e intervir sobre. Eles são as pistas para procurar entender o que está em jogo em na situação que se quer estudar.

A política pública investigada pela ANT é um processo-em-movimento, e ao perseguir os elementos que se associam em sua constituição, não será possível chegar a modelos, e sim a composições híbridas de co-formações políticas, de densidades de significado, de eixos de força e estabilidade não previstos. E, principalmente, prestar atenção a dois modos de produção de significado que comumente são apartados do fazer político e ficam de fora da trama de relações que aglutina os diversos tipos de agência. O primeiro é aquele que frequentemente dá origem às informações que, ao circularem como imparciais e técnicas, embasam a tomada de decisões e a 
formação de agenda, quando na verdade são redes de elementos cuja associação demandou muito trabalho e negociação. O segundo é o universo de produção de documentos, textos e imagens políticas que "ficam só no discurso" ou "não saem do papel". Nem o primeiro é técnico, e nem o segundo é cultural. Ambos se inscrevem em suportes materiais e categorias que são em si redes de acumulação de associações que fazem parte da política pública enquanto tais, e não por sua verossimilhança com uma realidade externa. Ao descartar o critério de verossimilhança, sua análise não só se torna possível como desejável, e entenderemos que são tão políticos quanto o político.

\section{Desenvolvimentos da Abordagem Relacional}

Pode-se observar que houve uma expansão dos fatores que a abordagem relacional passou a levar em conta desde seu surgimento. Dois fatores são claramente visíveis nessa evolução: (i) a inserção de elementos discursivos, culturais e textuais e (ii) a retomada da questão da agência humana (e não-humana). Quanto ao primeiro ponto, vemos o surgimento de uma sociologia cultural das redes. Como dizem Smith-Doerr e Powell (2006): "sabemos muito mais sobre os efeitos das redes do que sobre os fatores que as geram, as sustentam e as reproduzem.” Esta deficiência na área decorre tanto do foco excessivamente macro-estrutural dos estudos em ciência política e sociologia política, quanto até mesmo dos próprios estudos que utilizam a teoria de redes de um modo estruturalista mais determinista ou instrumentalista (EMIRBAYER e GOODWIN, 1994), a exemplo do primeiro conjunto de estudos apresentados nesse artigo. No primeiro caso, o foco generalista e o uso de conceitos abstratos como cultura política não permitem compreender como estruturas de relacionamento específicos agem na mudança institucional do Estado. Segundo Durkheim, a solidariedade orgânica de um sistema social não reside na cognição dos homens, mas na ligação e interação entre relacionamentos sociais objetivamente definidos. Mesmo na teoria de redes mais convencional, a negligência de aspectos como as crenças e valores dos atores e do significado dos discursos culturais e políticos na história dificulta a compreensão a das continuidades e rupturas dos processos sobre os quais se debruça. O excessivo caráter estrutural da análise de redes tradicional, por vezes determinista ou funcionalista, (ANSELL, 2006) não é capaz de captar a tensão permanente entre estrutura, cultura e agência (EMIRBAYER e GOODWIN, 1994). A análise de redes, contudo, pode tornar 
adequada para discutir essa tensão ao reconhecer os limites do estruturalismo excessivo. Ao fazêlo, abrem espaço para a discussão de elementos tão importantes como a constituição de identidades, a formação de discursos, e diferentes formas de valoração de grupos sociais.

Utilizando o conceito de cultura política, porém com uma abordagem de redes mais formal, Ansell (1997) analisou as estatísticas de voto dos sindicalistas franceses do fim do século XIX e identificou que o símbolo de greve geral criou um framework interpretativo compartilhado por sindicatos concorrentes, o que gerou uma coesão do movimento de trabalhadores. O símbolo foi disseminado por uma rede criada pelas chamadas bourses du travail, organizações representativas de vários sindicatos de trabalhadores. Esse e outros estudos passaram a levar em conta o potencial transformador de construtos culturais e compromissos normativos na ação social. Ikegami (2006) analisa como que as redes construídas nas práticas de apresentação de teatro japonesas da Era Tokugawa possibilitou o surgimento de uma identidade cultural que muito influenciou a formação do Estado-Nação japonês. Harrison White (1992; 2008) rompeu com o estruturalismo da análise de redes teoricamente ao inserir as relações sociais dentro de domínios compostos por redes e discursos. Esses domínios são co-constituídos ao redor de "histórias" que moldam percepções, comportamentos e identidades dos agentes sociais. David Stark (2009) passou a se utilizar do conceito de "princípios de avaliação" que, adotados por agentes que geralmente se encontram em diferentes redes sociais, são utilizados para justificar seus comportamentos e opiniões. Algumas escolas teórico-metodológicas das disciplinas avizinhadas, como a história social e a psicologia social, têm mais facilidade e familiaridade de incorporar elementos de ordem simbólica, discursiva ou material em seus estudos (SPINK et al, 1999) Na história, por exemplo, José Murilo de Carvalho apresenta a proclamação da República como um percurso de criações simbólicas do fato, do mito, de símbolos oficiais, de heróis como Tiradentes e de recriações de memórias políticas. O imaginário deixa de ser uma reificação apartada e é colocado como instrumento político importante (CARVALHO, 1990). Estudos como esses comprovam que uma abordagem mais dinâmica das redes sociais, utilizando-se estudos históricos e uma metodologia qualitativa que incorpore diferentes extensões espaciais e temporais e diversifique suas fontes, pode dar maior ênfase ao conteúdo dos laços da redes e explicar melhor processos de transformação de identidades e mudanças sociais (EMIRBAYER e GOODWIN, 1994). 
Se as formações culturais e estruturas sociais são interligadas, é por meio da ação humana documentável, dos produtos humanos, que essas esferas se relacionam empiricamente. A formação de discursos e narrativas culturais e redes sociais são realizados simultaneamente por meio da agência humana. Assim, a autonomia da agência humana é possível não somente por seus relacionamentos (SIMMEL, 1955), como também por sua localização entre estruturas culturais, discursos e narrativas (EMIRBAYER e GOODWIN, 1994). O conceito de empreendedor institucional formulado na sociologia organizacional, por exemplo, pode servir para incorporar a agência humana e a cultura à abordagem relacional. Esses empreendedores facilitam a cooperação entre agentes dispersos, heterogêneos e desagregados. Segundo Fligstein (2001), “esses atores não tem apenas uma ideia, mas devem usá-la para induzir a cooperação entre outros.” Esse papel de empreendedorismo tende a ser cada vez mais importante para o Estado ou os agentes estatais, visto que eles são geralmente os receptores das diversas demandas sociais e organizacionais, tendo que conciliar diversos interesses em jogo em cada projeto. Stark e Bruszt (1998) explicitam com clareza a atividade realizada: "Preparando esses programas como formas específicas de contabilidade/narrativa, os políticos (bem sucedidos) exploram o caráter duplamente associativo dos recursos - como vínculos entre grupos e como ligações no interior de redes de categorias que se constituem em princípios legitimadores. O trabalho de forjar e manter um programa político sempre envolve reagrupar recursos políticos - rearranjar os elos sociais entre grupos e fazer novas "associações" entre as categorias políticas e cognitivas através das quais a sociedade se representa. Fazendo estas associações, eles não apenas representam interesses (simplesmente marcando presença no campo político já dado e com posições fixas), mas principalmente os reconfiguram mediante o estabelecimento de novas conexões entre eles, às vezes aparentemente contraditórias. Colocando de forma diferente, as narrativas de um programa político não apenas representam interesses: elas reconstroem identidades.” Como já explicado, a perspectiva da ANT também transforma radicalmente a noção de agência e, consequentemente, de empreendedorismo, que passa a incorporar a mobilização de redes de materiais e técnicas, já que tanto humanos quanto não-humanos agem e formam as actor-networks que constituem programas antropológicos da realidade social e natural. Observar os elementos não-humanos abre todo um campo de investigação sobre o que deve ser levado em conta na análise da gestão e da política pública e os efeitos que essas associações são capazes de gerar. 


\section{Outras perguntas para outras respostas}

Os estudos da gestão pública e das políticas públicas sempre tenderam a duas direções: uma mais macro-sociológica de estruturas e sistemas, que produziriam certos resultados políticos, ou uma abordagem individualista que procura analisar os condicionantes da decisão dos fatores políticos (MARQUES, 2007). A abordagem relacional tem muito a contribuir para este debate. Os processos políticos envolvem relações de barganha e coordenação entre grupos de interesse, agências públicas ou nações. Podemos utilizar conceitos como coalizões, facções ou alianças para compreender essa coordenação. Porém, para a abordagem de redes, é precisamente o tipo de relação ou conexão dentro dessas coalizões que pode explicar os resultados políticos. As relações possuem prioridade sobre categorias, atributos e características intrínsecas ou essenciais (EMIRBAYER e GOODWIN, 1994). Nesse sentido, a perspectiva de políticas em rede procura ir além das já tradicionais teorias pluralistas e de elites (ou corporativistas) na tentativa de explicar a formação e implementação de políticas públicas. Da mesma forma, para a abordagem relacional, as organizações que compõem o jogo político “não são meras estruturas estáticas com limites claramente definidos" (MARTES, 2006). Do ponto de vista metodológico, podemos dizer que a abordagem de redes permite que se faça pesquisas longitudinais, o que também é raro nos estudos de políticas públicas no Brasil.

A mais importante característica da abordagem relacional é que ela permite formular novas questões na pesquisa de gestão e políticas públicas. A análise de redes sociais nos permite indagar como as políticas são reproduzidas e se tornam permanentes; como as informações para sua execução são obtidas e quem as obtém; como os diferentes atores cooperam entre as diferentes organizações governamentais; como a burocracia é constituída por meio de relações sociais (MARTES, 2006); e como o Estado e a sociedade civil participam da formulação de políticas públicas. O Institucionalismo de Redes traz, por exemplo, as questões sobre como melhor organizar a gestão pública para que esta seja mais eficiente e democrática, e como que o desenvolvimento econômico e social se associa a diferentes formas de participação política da sociedade civil. A ANT traz ainda uma série de questões que não poderiam ser formuladas pelas perspectivas anteriores; sobre o que é possível governar; como é possível governar; como as políticas públicas constroem seus próprios objetos de governo; quem participa dessa construção; como as políticas públicas acabam definindo o que é pra ser de controle do Estado e o que é pra se de controle da sociedade; como as políticas e a gestão pública acabam definindo o que é o 
próprio Estado; ou, em termos mais gerais, quais as associações entre atores, materialidades e discursos que são feitas para que se seja possível governar.

O objetivo deste artigo foi demonstrar que, ao introduzir uma abordagem relacional na análise da burocracia, da gestão pública e das políticas públicas, torna-se possível perguntar outras questões que ainda não foram colocadas nos estudos da área no Brasil. Dessa forma, podemos entender melhor como são formuladas, executadas e geridas as políticas públicas de governo. Em outras palavras, a abordagem relacional é relevante para compreender a arte de governar. Talvez não precisemos de uma "gramática” para entender o Estado e suas políticas, mas sim de uma abordagem relacional, focada em políticas e ações específicas de governo, construídas ao longo do tempo na inter-relação de atores, materialidades e discursos.

\section{Bibliografia}

ABRAMOVAY, R.; MAGALHÃES, R. O acesso dos agricultores familiares aos mercados de biodiesel: parcerias entre grandes empresas e movimentos sociais. Discussion Paper, USP e Plural Consultoria, 2007.

AMIN, A.; THRIFT, N. Institutional Issues for the European regions: from markets and plans to socioeconomics and powers of association. Economy and Society, v. 24, n. 1, 1995.

ANSELL, C. Symbolic networks: the realignment of the French working class, 1887-1894. American Journal of Sociology, v. 103, n. 2, p. 359-390, 1997.

ANSELL, C. The networked policy: regional development in Western Europe. Governance: An International Journal of Policy and Administration, v. 13, n. 3, p. 303-333, 2000.

ANSELL, C. Network institutionalism, In: RHODES, R. et al. The Oxford Handbook of Political Institutions. Oxford: Oxford University Press, 2006.

BREVIGLIERI, M. Habiter l'espace du travail. perspectives sur la routine. Histoires Et Societés, n. 9, p. 18-29, 2004.

BURT, R. From structural holes: the social structure of competition, 1992. In: DOBBIN, F. The new economic sociology: a reader. Chapter 12. Princeton and Oxford: Princeton University Press, 2004.

CALLON, M. The laws of the markets. Oxford: Blackwell Publishers, 1998.

CALLON, M. Some elements of a sociology of translation: domestication of the scallops and the fishermen of Saint Brieuc Bay. In: BIAGIOLI, M. (Ed) The sciencer studies reader. New York/London: Routledge, 1999. p. 67-83. 
CALLON, M. What does it mean to say that economics is performative? In: MACKENZIE, D.; MUNIESA, F.; SUI, L. (Eds) Do economists make markets? Pricenton: Pricenton University Press, 2007.

CALLON, M.; LATOUR, B. Unscrewing the big leviathan: how actors macrostructure reality and how sociologists help them to do so. In: KNORR-CETINA, K. D.; CICOUREL, A. V. (Eds) Advances in social theory and methodology: toward an integration of micro- and macrosociologies. Boston: Routledge and Kegan Paul, 1981. p. 277-303.

CARDOSO, F. H. Autoritarismo e democratização. Rio de Janeiro: Paz e Terra, 1975.

CARVALHO, J. M. de. A formação das almas. O imaginário da República no Brasil. São Paulo: Cia das Letras, 1990.

CASTILLA, E. J.; HWANG, H. GRANOVETTER, E. GRANOVETTER, M. Social networks in Silicon Valley. In: LEE, C.-M.; MILLER, W. F.; HANCOCK, M. G.; ROWEN, H. S. (Eds) The Silicon Valley Edged. Stanford: Stanford University Press, 2000.

CICOUREL, A. Notes on the integration of micro - and macro-levels of analysis. In: CICOUREL, A.; KNORR-CETINA, K. (Eds) Advances in social theory and methodology. Toward an integration of micro - and macro-sociologies. Boston/London/Henley: Routledge and Kegan Paul, 1981.

CROZIER, M. The bureaucratic phenomenon. Chicago: University of Chicago Press, 1964.

CROZIER, M. ; FRIEDBERG, E. L'acteur et le système: les contraintes de l'action collective. Paris, Éditions de Seuil, 1977.

DOBBIN, F. Forging industrial policy: the United States, Britain, and France in the railroad age. Cambridge: Cambridge University Press, 1994.

DOBBIN, F. Comparative and Historical Approaches to Economic Sociology. In: SMELSER, N.; SWEDBERG, R. (Eds) The handbook of economic sociology. Princeton: Princeton University Press, 2006.

DOBBIN, F. The new economic sociology: a reader. Princeton: Princeton University Press, 2004.

DIANI, M.; MCADAM, D. Social movements and networks: relational approaches to collective action. Oxford: Oxford University Press, 2003.

DURKHEIM, E. The rules of sociological method. London: Free Press, 1964.

EMIRBAYER, M. Manifesto for a relational sociology. The American Journal of Sociology, v. 103, n. 2, p. 281-317, 1997. 
EMIRBAYER, M.; GOODWIN, J. Network Analysis, culture, and the problem of agency. The American Journal of Sociology, v. 99, n. 6, p. 1411-1454, 1994.

EMIRBAYER, M.; MISCHE, A. What is agency? The American Journal of Sociology, v. 103, $\mathrm{n}$. 4, 1998.

EVANS, P. Embedded autonomy: states and industrial transformation. Princeton: Princeton University Press, 1995.

EVANS, P. State-society synergy: government and social capital in development. Elsevier Science, 1996.

FAORO, R. Os donos do poder: formação do patronato político brasileiro. Porto Alegre: Globo, 1958.

FLIGSTEIN, N. Social skills and the theory of fields. The American Behavioral Scientist, v. 40, n. 4, p. 397-405, 1997.

GEERTZ, C. O saber local: novos ensaios em antropologia interpretativa. Tradução Vera Mello Joscelyne. Petrópolis: Vozes, 1997. p. 366.

GRANOVETTER, M. S. The strength of weak ties. American Journal of Sociology, v 78, n. 6, p. 1360-1380, 1973.

GRANOVETTER, M. S. Getting a job. Cambridge: Harvard University Press. 1974.

GRANOVETTER, M. S. Economic action and social structure: the problem of embeddedness. American Journal of Sociology, v. 91, n. 3, p. 481-510, 1985.

GOUVÊA, G. F. P. Burocracia e elites burocráticas no Brasil. São Paulo: Paulicéia, 1994.

HECLO, H. The issue networks and the executive establishment. In: KING, A. The new American Political System. Washington: American Enterprise Institute for Public Policy Research,1978

IKEGAMI, E. A Sociological theory of publics: identity and culture as emergent properties in networks. Social Research, n. 67, p. 998-1029, 2000.

IKEGAMI, E. Bringing culture into macrostructural analysis in historical sociology: some epistemological considerations. Poetics, v. 33, p. 15-31, 2005.

IKEGAMI, E. Bonds of Civility: aesthetic networks and the political origins of Japanese xulture. Cambridge: Cambridge University Press, 2005.

KLIJN, E. H. Redes de políticas públicas: una visión general. SAGE Publications, 1998. 
KNOKE, D. The sociopolitical construction of national policy domains. Minnesota, University of Minnesota, 2003.

KNOX, H.; SAVAGE, M.; HARVEY, P. social networks and the study of relations: networks as method, metaphor and form. Economy and Society, v. 35, n. 1, p. 113-140, 2006.

LATOUR, B. On recalling ANT. In: LAW, J.; HASSARD, J. Actor-network theory and after. Oxford: Blackwell and The Sociological Review: 1999. p. 15-25.

LATOUR, B. Reassembling the social - an introduction to actor-network-theory. Oxford: Oxford University Press, 2005.

LATOUR, B. Science in action, how to follow scientists and engineers through society. Cambridge: Harvard University Press, 1987.

LATOUR, B. Un dialogue sur les Deux systemes de sociologie. Disponivel em : www.brunolatour.fr. 2004.

LAUMANN, E. O.; KNOKE, D. The Organizational State: social choice in national policy domains. Madison: University of Wisconsin Press, 1987.

LAUMANN, E. O.; PAPPI, F. U. Networks of collective action: a perspective on community influence systems. New York: Academic Press, 1976.

LAW, J. Objects, spaces and others. Lancaster: Lancaster University, 2000.

LAW, J. Actor network theory and material semiotics. Disponível em: www.heterogeneities.net/publications/law-antandmaterialsemiotics.pdf. Acesso em: 25 abr. 2007.

LOUREIRO, M. R. Os economistas no governo: gestão econômica e democracia. Rio de Janeiro: Fundação Getúlio Vargas, 1997.

MARQUES, E. C. Os mecanismos relacionais. Rev. bras. Ci. Soc. v.22 n.64 São Paulo junho, 2007.

MARQUES, E. C. Redes sociais e poder no estado brasileiro: aprendizados a partir das políticas urbanas. Revista Brasileira Ciências Sociais, v. 21, n. 60, 2006.

MARQUES, E. C. Estado e redes sociais: permeabilidade e coesão nas políticas urbanas do Rio de Janeiro. Rio de Janeiro: Revan/FAPESP, 2000.

MARTES, A. C. B. Relatório de Produtividade CNPQ. 2006.

MARTES, A. C. B. Relatório final do Projeto "Redes Sociais e Empresas". São Paulo, FGVEAESP, fev. 2005. 
MISCHE, A.; WHITE, H. Between Conversation and situation: public switching dynamics across network domains. Social Research, n. 65, 1998.

MOL, A. Ontological Politics. A word and some questions. In: LAW, J.; HASSARD, J. Actornetwork theory and after. Blackwell, 1999

NUNES, E. A gramática política do Brasil, clientelismo e insulamento burocrático. Rio de Janeiro: Jorge Zahar, 2003.

OLIVIERI, C. Política, burocracia e redes sociais: as nomeações para o alto escalão do Banco Central do Brasil. Revista de Sociologia Política, v. 29, p. 147-168, 2007.

PADGETT, J.; ANSELL, C. Robust action and the rise of the Medici: 1400-1434. American Journal of Sociology, v. 98, n. 6, p. 1259-319, 1993.

SIMMEL, G. On individuality and social forms. Chicago: Chicago University Press, 1971.

SMITH-DOERR, L.; POWELL, W. Networks and economic life. In: SMELSER, N.; SWEDBERG, R. The handbook of economic sociology. Second Edition. Princeton: Princeton University Press, 2006.

SMELSER, N.; SWEDBERG, R. The handbook of economic sociology. Second Edition. Princeton: Princeton University Press, 2006.

SMULLEN, A. Lost in translation? Shifting interpretations of the concept of 'agency': the Dutch case. In: POLLIT, C.; TALBOTT, C. Unbundled government: a critical analysis of the global trend to agencies, quangos and contractualisation. Routledge, 2004.

SPINK, M. J. (Org) Práticas discursivas e produção de sentidos no cotidiano: aproximações teóricas e metodológicas. São Paulo: Cortez, 1999.

SPINK, P. Possibilidades técnicas e imperativos políticos em 70 anos de reforma administrativa. In: BRESSER-PEREIRA, L. C.; SPINK, P. (Orgs) Reforma do Estado e administração pública gerencial. Rio de Janeiro: Fundação Getúlio Vargas, 1998.

STAR, S. L.; GRIESEMER, J. R. Institutional ecology, "translations" and boundary objects: amateurs and professionals in Berkeley's museum of vertebrate zoology, 1907-39. Social Studies Of Science, v. 19, n. 3, p. 387-420, 1989.

STARK, D. The sense of dissonance: accounts of worth in economic life. Princeton: Princeton University Press, 2009. (a ser publicado)

STARK, D.; BRUZST, L. Enabling Constraints: fontes institucionais de coerência nas políticas públicas no pós-socialismo. Revista brasileira de Ciências Sociais, v. 13, n. 36, 1998.

STEINER, P. A sociologia econômica. São Paulo: Editora Atlas, 2005. 
THOMPSON, G. F. Between hierarchies and markets: the logic and limits of networks forms of organization. Oxford: Oxford University Press, 2003.

WHITE, H. Identity and control. Princeton: Princeton University Press, 1992.

WHITE, H. Network switchings and bayesian forks: reconstructing the social and behavioral sciences. Social Research, v. 62, n. 4, p. 1035-1063, 1995.

Artigo recebido em 08/07/2008. Aprovado em 21/10/2008. 